\title{
Role of Electromagnetic Stimulation in the Treatment of Osteonecrosis of the Femoral Head in Early Stages
}

\author{
Juan L. Cebrián, Guillermo L. Milano, Alberto Francés, Yaiza Lopiz, Fernando Marco, \\ Luis López-Durán \\ Department of Orthopaedic Surgery, Hospital Clínico San Carlos, Madrid, Spain \\ Email: jcebrian.hcsc@salud.madrid.org
}

Received 18 February 2014; revised 22 March 2014; accepted 30 March 2014

Copyright (C) 2014 by authors and Scientific Research Publishing Inc.

This work is licensed under the Creative Commons Attribution International License (CC BY). http://creativecommons.org/licenses/by/4.0/

\begin{abstract}
Osteonecrosis of the femoral head is a disorder that leads to collapse and osteoarthritis in young patients. This study examines the effectiveness of pulsed electromagnetic fields [PEMF] in the treatment of osteonecrosis of the head in precollapse bone stages. A retrospective evaluation was done of 51 patients including 70 hips with symptomatic osteonecrosis of the hip treated with pulsed electromagnetic fields. Criteria for inclusion in the study group were evidence of osteonecrosis and absence of collapse of the femoral head. The average follow-up was 26 months (range, 18 - 90). Etiologies included idiopathic (40 cases), steroid use (26) and alcohol (4). To demonstrate the existence of osteonecrosis and its evolution, magnetic resonance imaging [MRI] and plain radiography techniques were used. Results: Procedures were radiological success in $80 \%$ of cases, and no progression to collapse in $\mathbf{8 8 . 5 7 \%}$ of hips. Eight of the $\mathbf{7 0}$ hips had radiographic progression to collapse. This study suggests that selected PEMF reduce the incidence of progression of osteonecrosis of femoral head in early stage.
\end{abstract}

\section{Keywords}

Osteonecrosis; Collapse; Pulsed Electromagnetic Fields; Magnetic Resonance Imaging

\section{Introduction}

Once radiographic changes are apparent, osteonecrosis in the adult generally follows a progressive course of femoral head collapse, joint incongruity, and secondary osteoarthritis. Because osteonecrosis occurs in young adults the orthopedist's goal should be to prevent this progression and to preserve the femoral head [1]-[4]. 
A number of prophylactic measures have been recommended, including core decompression, bone grafting, human bone morphogenetic protein, osteotomy, revascularization and electrical stimulation [3]. The results reported in the literature for these techniques have varied considerably [5]-[8].

Thanks to the widespread use of MRI it is possible to make the diagnosis of osteonecrosis in stages prior to the changes identified with plain radiographs.

Reports have been published concerning the early detection of symptomatic osteonecrosis but few studies have determined the results of treatment in this precollapse stage. The purpose of this study was to examine the effectiveness of PEMF in the treatment of osteonecrosis of the femoral head in the stages preceding bone collapse.

\section{Material and Method}

\subsection{Patients}

A retrospective evaluation was done of 51 patients (70 femoral heads) with symptomatic osteonecrosis of the hip treated with pulsed electromagnetic fields from January 1987 to January 2005. Criteria for inclusion in the study group were symptomatic lesion, evidence of avascular necrosis and absence of collapse on magnetic resonance images and X-ray, these criteria remained unaltered during all the period of study. According to the system of the Association Research Circulation Osseous (ARCO) [9] were considered eligible stage I or II osteonecrosis and excluded Stage III (subchondral collapse) or more. Patients who presented osteonecrosis after intracapsular hip fractures were excluded.

Finally a total of 70 hips were included in this study.

In 37 hips the side was right and in 33 was left. The mean age of the patients was 42 years (range 19 - 75 years); 31 (60.78\%) of the patients were men and 20 (39.21\%) women. The average follow up was 26 months (18 - 90).

As etiologic factors of the osteonecrosis of the hip were considered: 40 idiopathic; 26 related with steroid treatment; and 4 alcoholism.

\subsection{Clinical Evaluation}

Patients were assessed previous to the treatment and at three, six, twelve, twenty-four and forty-eight months after. A modified D’Aubigné scale was used to asses pain Table 1.

\subsection{Radiographic Evaluation}

Patients were selected for radiographic (anterior-posterior and axial X-ray) and magnetic resonance imaging examination for the time of each clinical assessment.

The heads were graded initially by the ARCO and FICAT methods (Figure 1). The ARCO method studies the stage of collapse and the volume of the osteonecrotic lesion based on MRI (Figure 2). The distribution was: ARCO I in 20 cases (28.57\%), and ARCO II in 50 cases (70.42\%) (Figure 3). ARCO III or more were not admitted to the study as collapse already had taken place (Table 2).

Radiographic progression was defined as an increase in ARCO stage or collapse more than $2 \mathrm{~mm}$ compared to pretreatment roentgenograms.

All radiographs were analyzed by people unaware of the treatment assignment. The volume of the femoral head and the osteonecrotic zone were then calculated by computer systems.

\subsection{Pulsed Electromagnetic Fields}

All the patients were treated with pulsed electromagnetic fields (IQL). PEMF were delivered by a pair of coils, mounted anterior and posterior. Technical features consisted of a single pulse configuration at low frequency (75 $\mathrm{Hz}$ ); Intensity: $400 \mathrm{~mA}$; Time of pulse: 1 at 3 milliseconds. The coils were held in place over the greater trochanter on a molded orthopaedic splint.

Patients wore the coils for eight hours per day for 6 months.

\section{Results}

Table 1 and Table 2 summarize the results before and after treatment with PEMF. 
Table 1. Clinical progression with modified Merle D’Aubigné scale.

\begin{tabular}{|c|c|c|}
\hline & Before treatment & After treatment \\
\hline I (severe, limitant) & 21 & 4 \\
\hline $\begin{array}{l}\text { II (pain is severe when walking, } \\
\text { prevents any activity) }\end{array}$ & 28 & 11 \\
\hline $\begin{array}{l}\text { III (pain is tolerable with limited } \\
\text { activity) }\end{array}$ & 12 & 5 \\
\hline $\begin{array}{l}\text { IV (pain is mild when walking; } \\
\text { it disappears with rest) }\end{array}$ & 5 & 15 \\
\hline $\begin{array}{l}\mathrm{V} \text { (pain is mild and inconstant; } \\
\text { normal activity) }\end{array}$ & 4 & 14 \\
\hline VI (no pain) & 0 & 21 \\
\hline
\end{tabular}

Table 2. ARCO stage progression.

\begin{tabular}{ccc}
\hline Stage & Before treatment & After treatment \\
\hline I & 20 & 20 \\
IA & 8 & 8 \\
IB & 6 & 6 \\
IC & 6 & 6 \\
II & 50 & 42 \\
IIA & 9 & 9 \\
IIB & 19 & 16 \\
IIC & 22 & 17 \\
Collapse & 0 & 8 \\
\hline
\end{tabular}

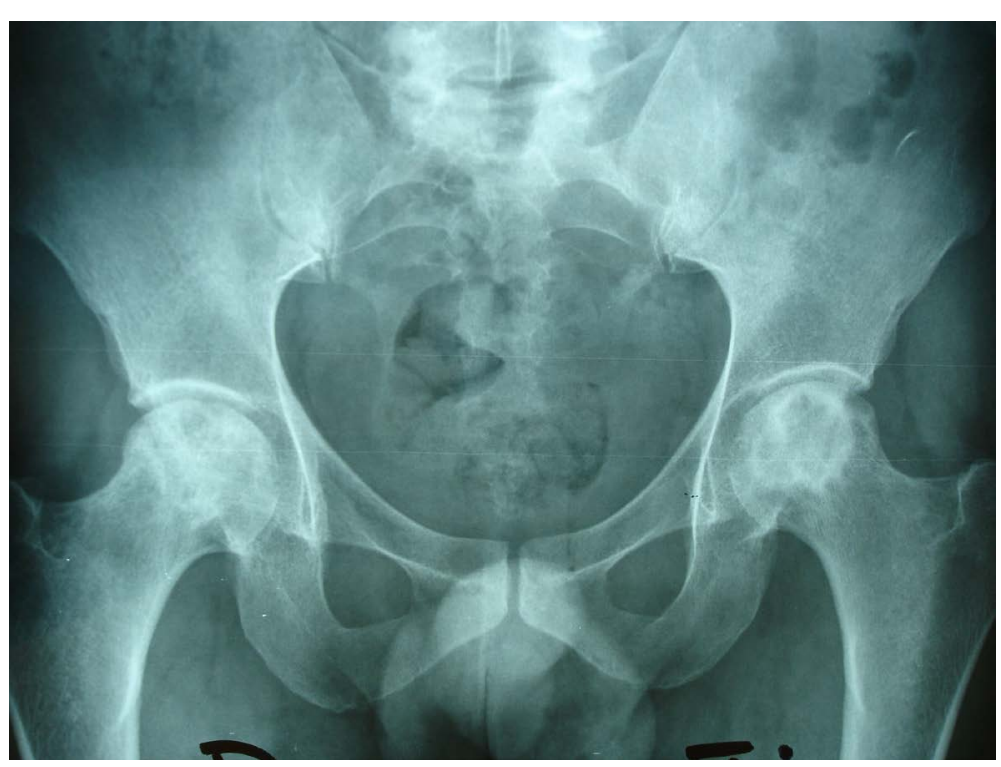

Figure 1. Pelvis AP Rx of a symptomatic 45-year-old patient with bilateral osteonecrosis stage FICAT II.

Clinical Changes: According to the D'Aubigne scale, 55 of the 70 hips (78.57\%) achieved clinical improvement, and 11 (15.75\%) kept a no worsening situation.

Radiographic Changes: in 8 cases (11.42\%) the femoral heads had collapsed. 


\begin{tabular}{|c|c|c|}
\hline \multicolumn{3}{|c|}{ Scheme of ARCO classification system (1992) } \\
\hline Stage & Radiological findings & Subclassification \\
\hline 0 & Positive: histology. Negative/normal: Radiograph/CT/MRI/Scintigraphy & - \\
\hline I & Positive: MRI and/or bone scintigraphy. Negative/normal: radiograph/CT & + '(a) \\
\hline II & Radiograph: sclerotic, cystic or osteoporotic changes of femoral head & + '(a) \\
\hline III & Radiograph: subchondral fracture (“crescent sign”) & + '(a) \\
\hline IV & Radiograph: flattening of femoral head & ++ '(b) \\
\hline V & $\begin{array}{l}\text { Radiograph: flattening of femoral head and osteoarthrotic changes: decreased joint } \\
\text { space and acetabular changes }\end{array}$ & ++ '(b) \\
\hline VI & Complete joint destruction & - \\
\hline
\end{tabular}

(a) Location of femoral head necrosis: 1) medial third, 2) median third, 3) lateral third. Size of femoral head necrosis: A) $<15 \%$, B) $15 \%-30 \%$, C) $>30 \%$. (b) Intrusion degree of femoral head contour: A) $<2 \mathrm{~mm}$, B) $2-4 \mathrm{~mm}$, C) $>4 \mathrm{~mm}$.

Figure 2. ARCO classification for osteonecrosis.

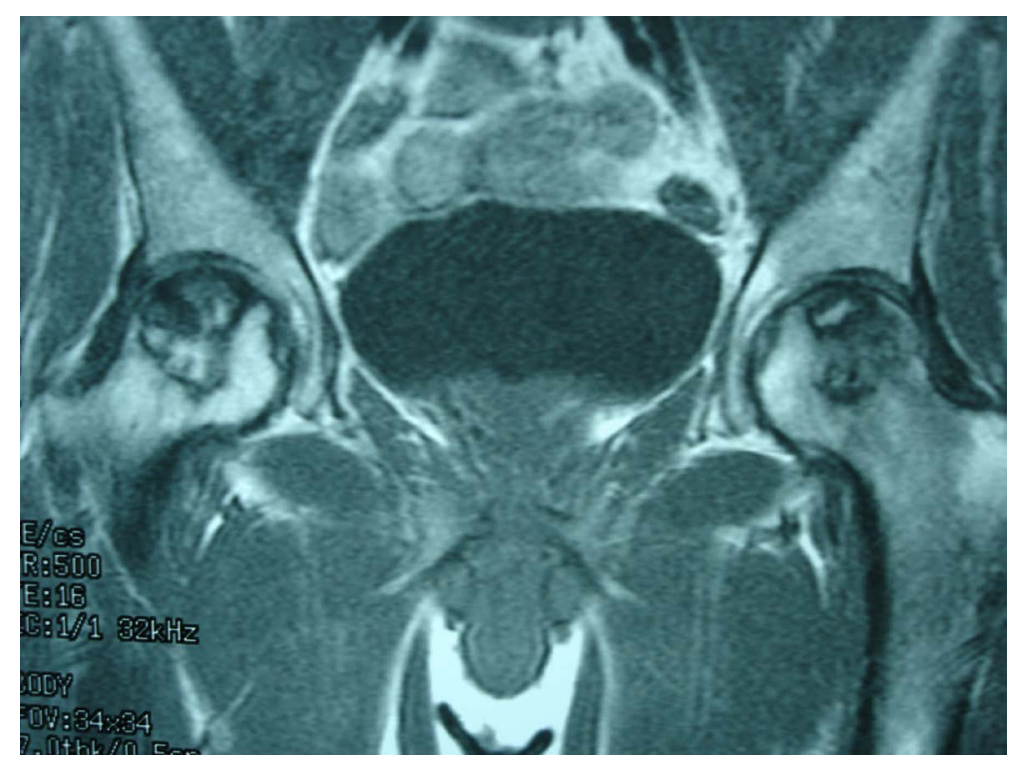

Figure 3. MR (TR: 500, TE: 16) that shows the same pelvis. No collapse and volume with osteonecrosis greater than $30 \%$ of the heads can be seen (ARCO IIC) in both hips.

Of the 50 hips that had been classified as stage II, 8 progressed to stage III. The survival percentage for the heads in stage I and II was 88.57\% (Figure 1 and Figure 4).

In relation with the degree of volume involvement: 17 heads initially classified as ARCO stage IA and IIA (those in which the maximum extent of the necrosis is less than 15 per cent of the head) did not collapse, and the survival percentage was 100 per cent; of 25 hips graded IB and IIB (15 to 30 per cent of involvement of the hip), three heads progressed to collapse; of the 28 heads in stage IC and IIC (more of 30\%), 5 (17.85\%) progressed to collapse. Of the 53 heads with a volume of necrotic lesion greater than 15\% (ARCO B, and C) 8 collapsed (15.09\%). All eight heads with radiographic progression of the hip had mainly lateral involvement.

\section{Discussion}

The natural history of this disease is still unclear. Nevertheless some studies have demonstrated a poor prognosis with higher than $70 \%$ - $90 \%$ of collapse rate at two years when hips in precollapse stage were left untreated [1] [4] [10]-[12].

MRI has revolutionized the diagnosis of osteonecrosis, as it allows identifying it on early stages, quantifying 


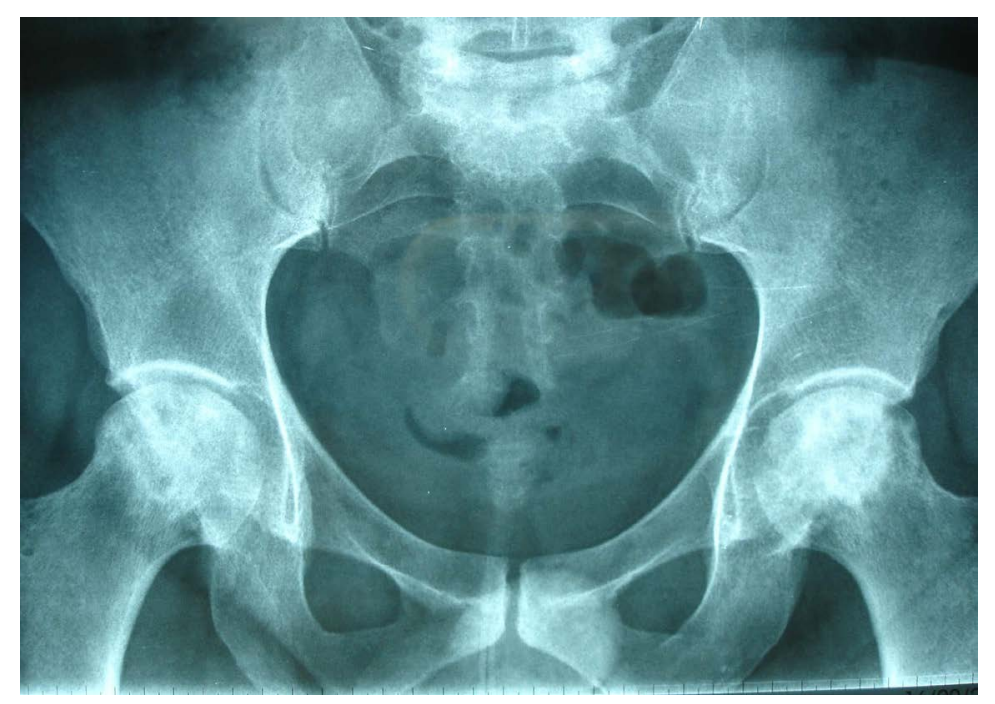

Figure 4. AP radiograph of pelvis that shows the same hip at 6 years follow up after treatment with PEMF. No collapse and no joint depression can be seen.

lesion volume and collapse degree. These characteristics also facilitate the development of classification systems.

A number of treatments have been recommended, including core decompression, bone grafting, osteotomy, revascularization and electrical stimulation [14]. There is, however, much disagreement about its effectiveness and complication rate. The rate of success reported in the literature has varied from $40 \%$ to $90 \%$ [1]-[3] [5]-[8] [10]. Few randomized trials have assessed the results.

Electrical stimulation has been shown experimentally to enhance osteogenesis and neovascularization as well as to alter bone turnover [15]-[17]. Many previous studies have shown the effect of the signal on both bone and cartilage cells [18] [19]. It can aid in the healing of fracture non-union and induce bone neoformation [20] [21].

Aaron [9] [22] and other authors [23] reported the effectiveness of PEMF and core decompression in the treatment of osteonecrosis of the femoral head.

A follow-up period of forty-eight months was chosen because collapse of the femoral head generally occurs over this span of time [12] [24].

Eight of these heads progressed to major stages. Progression for all hips in this study was $11.42 \%$. Progression to collapse of the 53 heads with a volume of the necrotic lesion more than 15\% (ARCO B and C) was $15.09 \%$. The overall success of the heads with a great volume affected was $84.9 \%$.

Patients with involvement of the head of more than $15 \%$ and lateral surface affected had poorer prognosis than other patients.

One interesting finding of the study was that 55 of the 70 hips had successful clinical results concerning to pain, and 66 of 70 did not worsen. Other studies showed this analgesic effect [9] [22] [23].

We consider as limitations of this study its retrospective nature and the fact that it only analyzes one kind of treatment, but nevertheless the initial goal was not to compare but to examine PEMF effectiveness.

Stimulation with PEMF is a low morbidity procedure; so far there have been no complications associated with this technique and the patients can be treated as outpatients. The cost of this treatment is less than combined cost of hospitalization, anesthetic and surgical procedure.

This study suggests that selected PEMF reduce the incidence of radiographic progression of symptomatic osteonecrosis of femoral head in early stages and provides successful clinical results. The diagnosis must be made in precollapse stage, through MRI, ideally before any changes appear on ordinary radiographs.

\section{References}

[1] Koo, K.-H., Kim, R. and Ko, G.-H. (1995) Preventing Collapse in Early Osteonecrosis of the Femoral Head: A Randomized Clinical Trial of Core Decompression. Journal of Bone and Joint Surgery, 77, 8.

[2] Mont, M.A., Carbone, J.J. and Fairbank, A.C. (1996) Core Decompression versus Nonoperative Management for Os- 
teonecrosis of the Hip. Clinical Orthopaedics and Related Research, 324, 169-178. http://dx.doi.org/10.1097/00003086-199603000-00020

[3] Mont, M., Jones, L., Seyler, T. and Marulanda, G. (2007) New Treatment Approaches for Osteonecrosis of the Femoral Head: An Overview. In Adult Reconstruction Hip. AAOS Instructional Course Lectures, 56, 221-233.

[4] Carsi, B., Gimeno, M., López-Oliva, F. and López-Durán, L. (1996) Utilidad de los campos electromagnéticos en el tratamiento de la Necrosis avascular de cadera: Estudio prospectivo de 30 casos. Revista Clínica Española, 196, 67-74.

[5] Song, W.S., Yoo, J.J., Kim, Y.M. and Kim, H.J. (2007) Results of Multiple Drilling Compared with Those of Conventional Methods of Core Decompression. Clinical Orthopaedics and Related Research, 454, 139-146. http://dx.doi.org/10.1097/01.blo.0000229342.96103.73

[6] Mont, M.A., Ragland, P.S. and Etienne, G. (2004) Core Decompression of the Femoral Head for Osteonecrosis Using Percutaneous Multiple Small Diameter Drilling. Clinical Orthopaedics and Related Research, 429, 131-138. http://dx.doi.org/10.1097/01.blo.0000150128.57777.8e

[7] Soucacos, P.N., Beris, A.E., Malizos, K., Koropilias, A., Zalavras, H. and Dailiana, Z. (2001) Treatment of Avascular Necrosis of the Femoral Head with Vascularized Fibular Transplant. Clinical Orthopaedics and Related Research, 386, 120-130. http://dx.doi.org/10.1097/00003086-200105000-00016

[8] Hasegawa, Y., Iwata, H., Torii, S., Iwase, T., Kawamoto, K. and Iwasada, S. (1997) Vascularized Pedicle BoneGrafting for Nontraumatic Avascular Necrosis of the Femoral Head: A 5- to 11-Year Follow-Up. Archives of Orthopaedic and Trauma Surgery, 116, 251-258. http://dx.doi.org/10.1007/BF00390047

[9] ARCO (Association Research Circulation Osseous) (1992) Committee on Terminology and Classification. ARCO News, 4, 41-46.

[10] Aaron, R., Lennox, D., Bunce, G. and Ebert, T. (1989) The Conservative Treatment of Osteonecrosis of the Femoral Head. A Comparison of Core Decompression and Pulsing Electromagnetic Fields. Clinical Orthopaedics and Related Research, 249, 209-218.

[11] Shimizu, K., Moriya, H., Akita, T., et al. (1994) Prediction of Collapse with Magnetic Resonance Imaging of Avascular Necrosis of the Femoral Head. Journal of Bone and Joint Surgery, 76, 215-223.

[12] Ohzono, K., Saito, M., Takaoka, K., Ono, K., Saito, S., Nishina, T., et al. (1991) Natural History of Nontraumatic Avascular Necrosis of the Femoral Head. Journal of Bone and Joint Surgery, 73, 68-72.

[13] Aiello, M.R. and Utica, N.Y. (2006) Imaging in Avascular Necrosis of the Femoral Head [Internet]. Utica, NY. http://emedicine.medscape.com/article/386808

[14] Jones, L. and Hungerford, D. (2007) The Pathogenesis of Osteonecrosis. In Adult Reconstruction Hip. AAOS Instructional Course Lectures, 56, 179-196.

[15] Adair, R.K. (1991) Biological Effects on the Cellular Level of Electric Field Pulses. Health Physics, 61, 395-399. http://dx.doi.org/10.1097/00004032-199109000-00009

[16] Cooper, M.S. (1995) Membrane Potential Perturbations Induced in Tissue Cells by Pulsed Electric Fields. Bioelectromagnetic, 16, 255-262. http://dx.doi.org/10.1002/bem.2250160408

[17] Pan, X., Xiao, D., Zhang, X., Huang, Y. and Lin, B. (2009) Study of Rotating Permanent Magnetic Field to Treat Steroid-Induced Osteonecrosis of Femoral Head. International Orthopaedics, 33, 617-623. http://dx.doi.org/10.1007/s00264-007-0506-7

[18] Massari, L., Fini, M., Ruggero, C., Stefania, S. and Traina, G. (2009) Biophysical Stimulation in Osteonecrosis of the Femoral Head. Indian Journal of Orthopaedics, 43, 17-21. http://dx.doi.org/10.4103/0019-5413.45319

[19] Ongaro, A., Pellati, A., Masieri, F.F., Caruso, A., Setti, S., Cadossi, R., Biscione, R., Massari, L., Fini, M. and De Mattei, M. (2011) Chondroprotective Effects of Pulsed Electromagnetic Fields on Human Cartilage Explants. Bioelectromagnetics, 32, 543-551. http://dx.doi.org/10.1002/bem.20663

[20] Brighton, C., Shaman, P. and Heppenstall, B. (1995) Tibial Non-Union Treated with Direct Current; Capacitative Coupling; or Bone Graft. Clinical Orthopaedics and Related Research, 321, 223-227.

[21] Scott, G. and King, J.B. (1994) A Prospective; Double-Blind Trial of Electrical Capacitative Coupling in the Treatment of Non-Union of Long Bone. Journal of Bone and Joint Surgery, 76A, 820-825.

[22] Aaron, R.K. and Stemberg, M.E. (1991) Electrical Stimulation of Osteonecrosis of the Femoral Head. Seminars in Arthroplasty, 12, 214-221.

[23] Basset, C.A., Scihnk-Ascani, M. and Lewis, S.M. (1989) Effects of Pulsed Electromagnetic Fields on Steinberg Ratings of Femoral Head Osteonecrosis. Clinical Orthopaedics and Related Research, 246, 172-185.

[24] Ozhono, K., Saito, M., Sugano, N., et al. (1992) The Fate of Nontraumatic Avascular Necrosis of the Femoral Head. A Radiological Classification to Formulate Prognosis. Clinical Orthopaedics and Related Research, 277, 73-78. 